\title{
Early Diagnosis of Pancreatic Cancer by Nerve Growth Factor Receptor
}

\author{
Messripour M*, Yzdanie-Kachoei R and Jaafari M \\ Department Clinical Biochemistry, School of Pharmacy and Pharmaceutical Sciences, Isfahan \\ University of Medical Sciences, Iran
}

*Corresponding author: Professor Manoochehr Messripour, Department Clinical Biochemistry, School of Pharmacy and Pharmaceutical Sciences, Isfahan University of Medical Sciences, Isfahan, Tel: +9836691590; Email: mesripour@hotmail.com

\section{Case Report \\ Volume 5 Issue 1}

Received Date: April 01, 2020

Published Date: April 30, 2020

DOI: $10.23880 /$ ijbp-16000173

\section{Abstract}

Pancreatic cancer in many cases can't be detected until cancer has progressed and spread to other parts of the body. The cancer prognosis is subject to a great deal on the stage of the disease at the time of diagnosis. In this case-control study, the levels of truncated NGF receptor of a 54-year-old man diagnosed with metastatic adenocarcinoma were measured and compared with that of a healthy subject. NGFR levels were found in the urine samples collected from both patient and control subjects with significantly higher levels in the patients as compared to those of control subject This finding suggests that the urinary truncated NGF receptor has the competency to be taken as a molecular biomarker for prognosis of pancreatic cancer.

Keywords: Biomarker; Neurotrophic factor; NGF receptor; Pancreatic cancer

\section{Introduction}

Nerve growth factor (NGF) is a neurotrophic factor and neuropeptide primarily involved in the regulation of growth, maintenance, proliferation, and survival of certain target neurons. NGF roles begin in development and extend throughout life, and involve a variety of neurons and nonneural cells. Particular attention is now given to a growing body of evidence that suggests that among other roles, endogenous NGF signaling provides target cell protective and repair functions [1-3]. Recent studies indicated that NGF exerted both stimulatory and inhibitory effects on certain non-neuronal tumors $[4,5]$. The specific biological functions of NGF actions are modulated via the specific NGF receptors (NGFR) localized on the target cells. The common NGFR (p 75 Neurotrophin receptor) is highly expressed during embryonic development and down-regulated to a trace detectable level during post-maturation phase, but pathological factors stimulate its synthesis and release the extracellular parts of the receptors as truncated soluble forms (Trk) to biological fluids [6,7]. It is proposed that NGFR might be considered as a paramedical measure in the prognosis of certain cancer [8-11]. Pancreatic cancer is known as one of the most dangerous types of cancer that result in mortality [12]. Awareness of early manifestations may lead to further investigation and diagnosis of presymptomatic disease before it becomes incurable. However, a clinical biomarker based on risk factors would help the probability of the disease and facilitate clinical decision making for further retrospective and prospective studies. The objective of this case study was to inspect NGFR in urine samples collected from a patient with pancreatic cancer.

\section{Patient and Methods}

A 54-year-old man presented to his primary care physician because of continued abdominal pain, chronic back pain, and hyperlipidemia. An abnormal mass in the pancreas was reported by computed tomography (CT) scan. Pathological examination revealed metastatic adenocarcinoma of the pancreas. Physical examination was otherwise unremarkable. A healthy volunteer subject with no clinical evidence of cancer was included as a control. The first-morning urine samples were collected in six consecutive 


\section{International Journal of Biochemistry \& Physiology}

days and urine NGFR was assayed on the same day. Agarose gel diffusion and indirect quenching fluoroimmunoassay were used to detect and measure urine NGFR levels using fluorescein-labeled NGF [13]. Agarose containing fluorescein-labeled NGF (FNGF) layered on a plastic plate and, urine samples taken from patient and control subjects were pipetted into the gel wells. The radial band around the wells was considered as positive. The competitive selectivity of anti-fluorescein and NGFR for binding to FNGF was assayed using a Perkin-Elmer spectrophotofluorimeter with the excitation wavelength of $495 \mathrm{~nm}$ and an emission wavelength of $540 \mathrm{~nm}$. The amount of NGFR is expressed as $\mathrm{ng} / \mathrm{ml}$ of FNGF which remained fluorescent.

\section{Results}

NGFR were found in all of the specimens collected daily for six consecutive days by both fluoroimetric and gel diffusion techniques. Table 1 shows that the mean levels of NGFR in the urine samples from the patient is significantly higher as compared to that of control (p 0.05) as measured by fluoroimetric technique. A significant relationship was found between the levels of NGFR as measured by fluoroimmunoassay and that of agarose gel diffusion detection.

\begin{tabular}{|c|c|c|}
\hline Experiments & Fluoroimmunoassay & $\begin{array}{c}\text { Agarose gel } \\
\text { diffusion }\end{array}$ \\
\hline Patient & $342 \pm 44^{*}$ & +++ \\
\hline Control & $113 \pm 19$ & Undetectable \\
\hline
\end{tabular}

Table 1: NGF receptors and gel diffusion in the pancreatic cancer.

NGER was assayed by both fluoroimmunoassay and agarose gel diffusion in the urine samples from the patient and healthy individuals. Data are mean \pm SD values from six independent experiments.

Statistical level of significance was set at $* \mathrm{P}<0.005$.

\section{Discussion}

The early diagnosis of pancreatic cancer is often very challenging. This makes the disease one of the cancers with the worst survival rates. The higher levels of truncated NGFR observed in the patients, may be interpreted as being consistent with the up-regulation of NGF receptors in the cancer cell of the patients to represent an adaptive response to nerve growth factor. This is consistent with previously reported investigations $[14,15]$. It is evident that the pancreatic cancer cells expresses and releases more truncated nerve growth factor receptor into the biological fluids, which excreted by the urine [16,17]. This finding suggests that the urinary truncated NGF receptor has the competency to be taken as a molecular biomarker for the prognosis of pancreatic cancer. However, further studies of the degree and distribution of nerve growth factor and its receptor, and the possible relationship between the growth factor and the status of the basal pancreatic cell in vivo, are necessary before engaging in clinical trials.

\section{References}

1. Reichardt LF (2006) Neurotrophin-regulated signaling pathways. Philos Trans R Soc Lond BBiol Sci 361(1473): 1545-1564.

2. Gao C, Zhang L, Sun D, Li J, Yao X, et al. (2017) Roles of p75NTR in Maintaining Brain Hemostasis and Implications for p75NTR-targeted Therapies. Curr Alzheimer Res 14(5): 554-561.

3. Skaper SD (2008) The biology of neurotrophins, signaling pathways, and functional peptidemimetics of neurotrophins and their receptors. CNS Neural Disord Drug Targets 7(1): 46-62.

4. Orive G, Anitua E, Luis Pedraz J, Emerich DF (2009) Biomaterials for promoting brain protection, repair and regeneration. Nature Reviews Neurosci 10: 682-692.

5. Teng KK, Hempstead BL (2004) Neurotrophins and their receptors: signaling trios in complex biological systems. Cell Mol Life Sci 61(1):35-48.

6. DiStefano PS, Clagett-Dame M, Chelsea DM, Loy R (1991) Developmental regulation of human truncated nerve growth factor receptor. Ann Neurol 29: 13-20.

7. Messripour M, Nazarian A, Mesripour A, Mohammadi I (2015) Nerve growth factor receptors in dementia. Turk J Med Sci 45(5): 1122-1126.

8. Yang XQ Xu YF, Guo S (2014) Clinical significance of nerve growth factor and tropomyosin-receptor-kinase signaling pathway in intrahepatic cholangiocarcinoma. World J Gastroenterol 20(14): 4076-4084.

9. Dollé L, Adriaenssens E, Yazidi-Belkoura I, Le Bourhis X, Nurcombe V, et al. (2004) Nerve Growth Factor Receptors and Signaling in Breast Cancer. Current Cancer Drug Targets 4: 463-477.

10. Molloy NH, Read DE, Gorman AM (2011) Nerve Growth Factor in Cancer Cell Death and Survival. Cancers 3(1): 510-530.

11. Zhu ZW, Friess H, Wang L, Bogardus T, Korc M, et al. (2001) Nerve growth factor exerts differential effects on the growth of pancreatic cancer cells. Clin Cancer Res $7(1): 105-112$. 


\section{International Journal of Biochemistry \& Physiology}

12. Rawla P, Sunkara T, Gaduputi V (2019) Epidemiology of Pancreatic Cancer: Global Trends, Etiology and Risk Factors. World J Oncol 10(1): 10-27.

13. Messripour M, Moein S (1997) Indirect quenching fluororeceptorassay of anti-AChR antibodies. Mol Chem Neuropathol 31: 43-51.

14. Yan Q Johnson EM (1988) Immunohistochemical study of the nerve growth factor receptor in developing rats. J Neurosci 8(9): 3481-3498.
15. Shepheard SR, Chataway T, Schultz DS, Rush RA, Rogersmail ML (2014) The extracellular domain of neurotrophin receptor p75 as a biomarker for amyotrophic lateral sclerosis. PLOS ONE 9: 1-9.

16. Hackert T, Büchler MW (2013) Pancreatic cancer: advances in treatment, results and limitations. Dig Dis 31: 51-56.

17. Blondy S, Christou N, David V, Verdier M, Jauberteau MO, et al. (2019) Neurotrophins and their involvement in digestive cancers. Cell Death Dis 10(2): 123. 